\title{
Detecting temporal and spatial effects of epithelial cancers with Raman spectroscopy
}

\author{
Matthew D. Keller ${ }^{\mathrm{a}}$, Elizabeth M. Kanter ${ }^{\mathrm{a}}$, Chad A. Lieber ${ }^{\mathrm{b}}$, Shovan K. Majumder ${ }^{\mathrm{a}}$, Joanne Hutchings ${ }^{\mathrm{c}}$, \\ Darrel L. Ellis ${ }^{\mathrm{d}}$, Richard B. Beaven ${ }^{\mathrm{e}}$, Nicholas Stone ${ }^{\mathrm{c}}$ and Anita Mahadevan-Jansen ${ }^{\mathrm{a}, *}$ \\ ${ }^{a}$ Department of Biomedical Engineering, Vanderbilt University, Nashville, TN, USA \\ ${ }^{\mathrm{b}}$ CHOC Research Institute, Children's Hospital of Orange County, Orange, CA, USA \\ ${ }^{\mathrm{c}}$ Biophotonics Research Group and Department of Pathology, Gloucestershire Royal Hospital, Gloucester, \\ Gloucestershire, UK \\ ${ }^{\mathrm{d}}$ Division of Dermatology, Vanderbilt University Medical Center, Nashville, TN, USA \\ ${ }^{\mathrm{e}}$ Tri-State Women's Health, Florence, KY, USA
}

\begin{abstract}
Epithelial cancers, including those of the skin and cervix, are the most common type of cancers in humans. Many recent studies have attempted to use Raman spectroscopy to diagnose these cancers. In this paper, Raman spectral markers related to the temporal and spatial effects of cervical and skin cancers are examined through four separate but related studies. Results from a clinical cervix study show that previous disease has a significant effect on the Raman signatures of the cervix, which allow for near $100 \%$ classification for discriminating previous disease versus a true normal. A Raman microspectroscopy study showed that Raman can detect changes due to adjacent regions of dysplasia or HPV that cannot be detected histologically, while a clinical skin study showed that Raman spectra may be detecting malignancy associated changes in tissues surrounding nonmelanoma skin cancers. Finally, results of an organotypic raft culture study provided support for both the skin and the in vitro cervix results. These studies add to the growing body of evidence that optical spectroscopy, in this case Raman spectral markers, can be used to detect subtle temporal and spatial effects in tissue near cancerous sites that go otherwise undetected by conventional histology.
\end{abstract}

Keywords: Raman spectroscopy, optical diagnosis, cervix, dysplasia, skin cancer, malignancy associated changes, field effect, raft cultures, spectral markers

\section{Introduction}

Epithelial cancers are the most common type of cancers in humans, comprising over $90 \%$ of cancer cases [1]. They can arise from external, or surface epithelia, which include skin, cervix, large intestine, lung, and stomach; or internal epithelia, which include breast, prostate, ovary, bladder, and pancreas [1]. The epithelium is the most common cancer site because of the constant turn-over and repair of these cells, as well as possible exposure to environmental or other exogenous

${ }^{*}$ Corresponding author. Department of Biomedical Engineering, Vanderbilt University, Station B, Box 351631, Nashville, TN 37235 , USA. Tel.: +1 615343 4787; Fax: +1 615343 7919; E-mail: Anita.mahadevan-jansen@vanderbilt.edu. factors such as viruses. This paper will focus on two specific epithelial cancers, those of the cervix and the skin, both of which have been expressly targeted for interrogation by optical spectroscopy.

\subsection{Cervical cancer}

Each year up to 1 million women in the US are diagnosed with cervical dysplasia, most of whom are between the ages of 25-35. Without treatment, it is possible that $30 \%-50 \%$ of cases may progress to invasive cancer [2]. Most cervical dysplasias begin at the squamocolumnar junction, where the squamous and columnar epithelia meet, and can be divided into low grade squamous intraepithelial lesions (LGSIL, or mild dysplasia) and high grade squamous intraepithelial le- 
sions (HGSIL, or moderate and severe dysplasia and carcinoma-in-situ (CIS)) [3-5]. Many cervical lesions can be associated with infection by the human papilloma virus (HPV), which can produce characteristic epithelial proliferation leading to malignant transformations. There are several HPV strains that can induce this transformation, primarily strains 16 and 18 [3], which can be protected against by the Gardasil vaccine. However, over $80 \%$ of cervical cancer cases worldwide occur in developing countries [6], so it is expected that cervical cancer will continue to be a significant medical problem of the near future.

In current medical practice, an annual Pap smear is the primary screening method for cervical dysplasia. Although the incidence of cervical cancer in the US has decreased since the Pap smear became common practice, the incidence of cervical precancer has actually increased $[7,8]$. The specificity of the Pap smear is generally very high (around 95\%) [9], but its sensitivity can be as low as 20 to $50 \%$ depending on the prevalence of the disease within the population [10]. Colposcopy usually follows an abnormal Pap smear in the United States and is used to direct the taking of biopsies [8]. Colposcopy has a comparatively high degree of accuracy in pin-pointing the area and grade of lesions [11], but this procedure requires extensive training, and its sensitivity is variable and limited, even in the hands of expert practitioners [12]. To overcome these diagnostic shortcomings, a real-time, non-invasive tool that can not only detect cervical dysplasia but also follow the progression of cervical disease is needed. Such a tool could also be used as a "see and treat" method to detect disease and allow for treatment in a single visit to the doctor.

\subsection{Skin cancer}

Skin cancer is a major problem in the United States that continues to get worse [13]. The predominant forms of skin cancer: melanoma, basal cell carcinoma (BCC), and squamous cell carcinoma (SCC), account for over half of all cancer cases in the US, and nonmelanoma cancers (BCC and SCC) account for over $95 \%$ of the 1.3 million new cases of skin cancer each year [13]. BCC arises from the basal layer of the epidermis and can invade upward or downward into surrounding tissue, but it very rarely metastasizes. SCC arises from suprabasal keratinocytes and will occasionally metastasize as it locally invades tissue, typically toward deeper strata [13].
Current diagnostic methods for skin cancer rely on initial visual inspection, which can often err towards false positive diagnosis, and tissue biopsy, which is a subjective and slow procedure [13]. Since skin lesions often have irregular boundaries, both laterally and axially, it is important to determine their spatial extent to optimize treatment. Current methods to accomplish this, like Mohs micrographic surgery and various imaging modalities, suffer from speed and accuracy limitations as well [13]. There is thus a need for a realtime, non-invasive diagnostic tool that can accurately discriminate skin cancers from numerous other clinically normal or benign skin conditions, and that can be spatially precise enough to determine lesion margins. Similar needs exist for most forms of epithelial cancers, to improve both detection of cancerous lesions and guidance of therapy to treat them.

\subsection{Raman spectroscopy}

Raman spectroscopy is a non-invasive technique that uses inelastic light scattering to reveal information about the biochemical content of tissues. Several groups have taken advantage of Raman's sensitivity to subtle biochemical changes to detect spectral markers associated with cancer in many epithelial tissues and organs, including the cervix [14,15], bladder and prostate [16], lung [17], skin [18,19], breast [20,21], and the GI tract [22-24]. Due to their ease of access, the cervix and skin have seen some of the most extensive study.

\subsubsection{Raman spectroscopy of cervix}

Raman spectroscopy can be used to distinguish cervical precancers from normal and benign conditions $[25$, 26]. Although our group originally showed that Raman can do this fairly effectively ( $89 \%$ sensitivity and $81 \%$ specificity), questions have been raised about the sources of spectral variability as well as about the biological basis of the spectral differences. To examine the issue of true normal measurements, a small study was conducted to compare the normal spectra from the cervices of healthy patients to normal spectra from cervical dysplasia patients (unpublished work). The normal ectocervix from healthy and dysplasia patients appears identical histologically, but there are spectroscopic differences between the two sets of measurements. In recent work, it was discovered that cervical Raman spectra are sensitive to menopausal status and hormonal variations as well [27]. In fact, stratifying cervical spectra according to hormonal and menopausal 
status led to an increase in accuracy from $88 \%$ to $94 \%$ for classifying Raman spectra as normal, metaplasia, LGSIL, or HGSIL [28]. Since Raman is sensitive to these kinds of changes, it is possible that variations in previous cervical health would affect Raman signatures of currently normal tissue in a similar manner, and would need to be accounted for to further improve the ability of Raman to detect cervical dysplasia.

\subsubsection{Raman spectroscopy of skin}

Given the accessibility of the skin, several modalities of optical spectroscopy have been investigated for skin cancer diagnosis, but Raman spectroscopy has seen particular success [19,29-32]. In our lab, a purposebuilt handheld Raman microscope was constructed with an axial resolution of $14 \mu \mathrm{m}$ and lateral resolution of $1.2 \mu \mathrm{m}$ [33] for optimal control in obtaining measurements from and around various skin cancer lesions in vivo. This device was used in a previous in vitro study to discriminate among normal, BCC, SCC, and melanoma samples with near $100 \%$ classification accuracy, and $100 \%$ sensitivity and specificity in detecting cancer versus normal skin [34]. It was noted that focusing the objective at the surface or $40 \mu \mathrm{m}$ below the surface of the skin samples provided the best discrimination results, even though the lesions studied generally manifest in much deeper skin strata. This finding raised the question of whether these results are repeatable in vivo, and what kind of biochemical processes are occurring to allow detection of a deep tumor by Raman measurements obtained near the tissue surface.

\subsection{Malignancy associated changes}

One possible explanation for the previous findings mentioned above is the presence of so-called malignancy associated changes (MACs), a concept very similar to and sometimes used interchangeably with the idea of a cancer "field effect" [35,36]. MACs refer to biochemical changes, such as chromatin rearrangement, in visually and histologically normal cells in the vicinity of a tumor that can be detected with ultra sensitive techniques like high resolution cytometry. This idea was first proposed over 40 years ago [37-39], and more recent studies of tissues such as lung [40-42], cervix [43-46], and breast [47-49] have supported the idea.

A small but growing number of studies suggest that optical methods may be able to detect MACs. Backman et al. have shown the ability of enhanced elastic scattering spectroscopy and four-dimensional elas- tic light-scattering fingerprinting (4D-ELF) to detect pre-malignant changes in colon tissue of rats, mice, and humans [50-52]. More recently, the same group has developed a method to predict the presence of pancreatic cancer without direct visualization of the pancreas, instead taking measurements on the adjacent periampullary duodenal mucosa. Using 4D-ELF and low-coherence enhanced backscattering (LEBS) spectroscopy, they were able to discriminate between pancreatic cancer patients and normal controls with $95 \%$ sensitivity and $91 \%$ specificity [53].

\subsection{Tools for evaluating spectral disease markers}

Several methods can be used to evaluate and investigate the spectral disease markers present in Raman spectra of epithelial tissues. One can use an animal or tissue model to tightly control biological conditions prior to acquiring Raman spectra, or one could use microspectroscopy to attempt biochemical mapping or other similar analysis to try to extract more information out of the spectra.

\subsubsection{Organotypic raft cultures}

Organotypic raft cultures are in vitro models of epithelial tissues containing collagen and fibroblasts to model the dermis (stroma), and layers of differentiated keratinocytes to model the epidermis or other surface layer. The Raman spectra of these raft cultures have been shown to replicate the spectra of normal epithelial tissues quite faithfully, and the spectra of raft cultures with cancerous cells replacing keratinocytes also correspond to spectra of cancerous tissue samples [54]. Since the true mechanism underlying the ability of Raman to classify skin types is not known, there is a need to discover the natures and locations of the sources of the spectral variations that allow discrimination. Thus, raft cultures provide a useful medium for examining how the location of cancerous cells within an epithelial tissue affects the Raman spectral signatures of it, both as a whole and within individual layers. Measurements can easily be taken at multiple time points as well to investigate temporal effects of epidermal versus stromal disease.

\subsubsection{Raman microspectroscopy}

Many of the Raman spectral differences described above were seen with probe-based measurements on in vivo tissue, where the sampling volume is on the order of approximately $1-2 \mathrm{~mm}^{3}$. It is therefore important to understand the biochemical and morpholog- 
ic basis of the spectral markers of disease, as well as the basis for differences in the signatures of the tissues when developing a diagnostic technique. Raman micro-spectroscopy records spectroscopic information from tissue with high spectral and spatial resolution, and is thus a useful tool for understanding the biological basis of spectral-based tissue discrimination.

\subsection{Description of studies}

Although Raman spectroscopy has not been used specifically to detect malignancy associated changes or field effects in tissue, there is growing evidence that it may be capable of doing so, based on previous findings in the cervix and skin and on the biochemical specificity of the technique. In this paper, four separate but related studies are presented in which Raman spectroscopy appears to detect tissue changes not seen by conventional histology. These include a clinical study comparing spectra from histologically normal cervices of healthy patients versus those of patients with previous disease; an in vitro cervical mapping study examining the epithelial versus stromal spectral signatures for a sample containing disease only in the epithelial layer; a clinical skin study for discriminating nonmelanoma cancers from normal tissue via measurements taken from tissues outside the tumor margin; and a study using raft cultures to examine the epidermal and stromal contributions to spectra obtained from rafts with disease in the epidermis versus disease in the stroma.

\section{Materials and methods}

\subsection{Clinical cervix study}

A total of 102 patients undergoing a routine Pap smear were recruited to participate in the study as approved by the Copernicus and Vanderbilt Institutional Review Boards. To be eligible for enrollment, the patient had to be undergoing a routine Pap smear, be between the ages of 18-75, and still have a cervix. Informed consent was obtained from each patient prior to the procedure. The cervix was exposed and visually examined by the attending physician, and the Pap procedure was done according to standard clinical protocol. The cervix was wiped clean with a dry cotton swab, after which Raman measurements were taken from three locations on the ectocervix. The spectra were considered normal if the Pap smear was negative. The patient's age, last period date, use of artificial hor- mones, menopausal status, and any previous abnormal Pap smears were all noted upon chart review.

Raman spectra were collected using a portable Raman spectroscopy system consisting of a $785 \mathrm{~nm}$ diode laser (Process Instruments, Inc., Salt Lake City, UT), a beam-steered fiber optic probe (Visionex Inc., Atlanta, GA), an imaging spectrograph (Kaiser Optical Systems, Inc., Ann Arbor, MI), and a back-illuminated, deep-depletion, thermo-electrically cooled charge coupled device (CCD) camera (Roper Scientific, Inc., Princeton, NJ), all controlled with a laptop computer. Details of the system have been previously reported [55]. For each measurement, the fiber optic probe delivered $80 \mathrm{~mW}$ of incident light onto the tissue for 3 seconds, and the overhead fluorescent lights were turned off.

Spectral calibration of the system was performed each day using a neon-argon lamp and naphthalene and acetaminophen standards to correct for system wavenumber, laser excitation, and throughput variations. The spectra were processed for fluorescence subtraction and noise smoothing using the modified polynomial fit method, described previously [55]. Following data processing, each spectrum was normalized to its mean spectral intensity across all Raman bands to account for overall intensity variability.

A two-step, multi-class probabilistic algorithm was used to classify the data in this study [56]. In the first step, using maximum representation and discrimination feature (MRDF), the processed data set undergoes a two-part, non-linear transform to extract relevant features that provide the best class separation. The second step uses sparse multinomial logistic regression (SMLR) for classifying the MRDF output features into corresponding tissue categories - in this case, true normal versus a history of disease. An unbiased classification algorithm was developed using these two methods and was tested using leave-one-patient-out crossvalidation. Further details of this method have been previously described [56].

\subsection{In vitro cervix study}

Informed consent was obtained from patients undergoing LEEP excision and vaginal hysterectomy, and ethical approval for this study was obtained from the Gloucestershire Local Ethics Committee (IRB). Cervical tissue samples, which were typically $1 \mathrm{~cm}$ in diameter, were immediately snap frozen in liquid nitrogen upon excision. For each patient, their age, menopausal 
status, and date of last menstrual period (if applicable) were noted.

Frozen sections with a thickness of 15-20 microns were placed onto calcium fluoride slides for Raman spectral mapping and stored frozen until measured. Serial 7 micron sections from either side of the mapping section were obtained and stained with hematoxylin and eosin (H\&E) for histopathological evaluation. An expert pathologist annotated each sample with the different pathologies, including normal ectocervix epithelium, normal endocervix epithelium, transition zone, and LGSIL or HGSIL. Glands, stroma, and warts due to HPV were also identified for correlation with frozen sections.

After thawing the samples at room temperature, Raman spectra were acquired using a customized Renishaw System 1000 spectrometer with Streamline ${ }^{\mathrm{TM}}$ technology, a novel rapid technique for Raman data acquisition [57]. Raman spectra acquired from regions of interest identified by the pathologist were acquired with a spectral acquisition time of 40 seconds and step size of 12.7 microns in both $\mathrm{x}$ and $\mathrm{y}$ directions. Approximately 100 spectra were gathered from each region. Cosmic rays were removed, and background subtraction for each spectrum was achieved by iterative subtraction of a 5th order polynomial. Mean spectra were then calculated for the entire selected regions from the epithelium and the stroma of different pathologies. Mean Raman spectral features that differed among the various pathology groups were identified and correlated to biochemical findings in the literature.

\subsection{Clinical skin study}

The in-house-built Raman microspectrometer described above [33] was used to obtain Raman measurements from below the skin surface in 21 lesions from 19 patients with suspected basal cell carcinoma or squamous cell carcinoma. Informed consent was obtained from these patients under a protocol approved by the Vanderbilt IRB. Based on the results of a previous ex vivo skin cancer study [34], the clinical Raman spectra were obtained from a single measurement depth of $40 \mu \mathrm{m}$ below the skin surface, both within a suspected nonmelanoma lesion boundary and on adjacent perilesional skin assumed to be normal. After each Raman measurement, the location of the measurement was biopsied for histopathologic correlation, though perilesional sites were not pathologically correlated. The data processing and analysis were similar to those described for the clinical cervix study, with the discrimination algorithm classifying spectra according to histopathologic diagnoses.

\subsection{Raft culture study}

Three types of raft cultures were used in this study: normal, those with normal dermis (stroma) layers and SCC cells (human epidermoid squamous cell carcinoma, A-431) in the epidermis, and those with normal epidermis layers and SCC cells in the dermis. Normal rafts and rafts with SCC cells in the epidermis layer were constructed as described elsewhere [54]. For rafts with SCC cells in the stroma layer, SCC cells were mixed with normal fibroblasts (NHDF) in equal proportions, while keeping the total number of cells in the stroma constant compared with the other raft cultures. An earlier study in our lab had shown that there was no effect of varying the ratio of SCC to NHDF cells over an order of magnitude in either direction (unpublished work), so equal proportions were used for the sake of simplicity. Only normal keratinocytes (NHK) were used in the epidermal layer of these rafts, as for normal rafts. Four rafts of each of the three types were made for each experiment, and Raman spectral measurements were obtained using the same system as for the clinical cervix study, but with an integration time of five seconds. Raman measurements were taken at 10 , 15 , and 20 days following the formation of the rafts. After the last time point, one or two rafts of each type were fixed in $10 \%$ formalin for histological processing, and the remaining rafts had their epidermal and stromal layers separated and measured as previously described.

All spectra, processed and calibrated as for the two clinical studies, from each kind of raft at each time point were averaged, and these means were compared at each wavenumber with simple one-way ANOVA and/or a series of 2-sample t-tests. More complicated techniques were deemed unnecessary since the goal was not to develop a discrimination algorithm, but rather just to look for any significant differences.

\section{Results}

\subsection{Clinical cervix study}

Cervical tissue Raman spectra from patients with previous cervical disease but who currently have a healthy cervix (the "previous abnormal" category) and spectra from women who have had no history of cervical disease ("true normal") are shown in Fig. 1. There are consistent differences between the spectra at the $1250 \mathrm{~cm}^{-1}$ peak and at the shoulder around $1400 \mathrm{~cm}^{-1}$, among other more subtle and variable differences. Ta- 
Table 1

Confusion matrix for discriminating previous cervical disease versus true normals (i.e. no history of an abnormal Pap smear) with Raman spectroscopy

\begin{tabular}{cccc}
\hline & & \multicolumn{2}{c}{ Histopathology diagnosis } \\
\cline { 3 - 4 } & & True normal & Previous abnormal \\
\hline Raman & True normal & 109 & 0 \\
Diagnosis & Previous abnormal & 1 & 53 \\
\hline
\end{tabular}

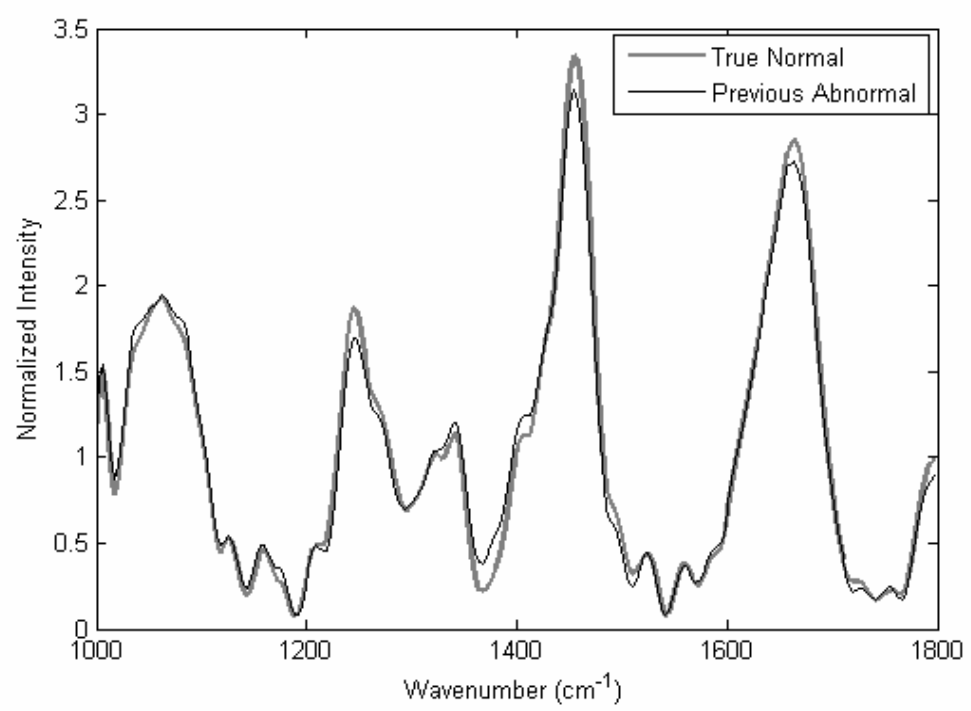

Fig. 1. Average Raman spectra from true normal cervices (110 spectra) and from cervices that are currently normal but with previous abnormal Pap smears (53 spectra).

ble 1 shows the confusion matrix for discriminating between these two conditions using probabilistic statistical methods. With only a single spectrum misclassified, the overall accuracy of Raman spectroscopy for determining whether or not a woman had a history of cervical disease was greater than $99 \%$.

\subsection{Raman microspectroscopy of HPV changes in cervix}

Using a Raman microspectroscopy system, Raman spectra were acquired from an in vitro cervix sample that had both normal ectocervix and LGSIL associated with mild HPV changes, as determined by an expert pathologist. Average spectra from normal ectocervix and LGSIL regions are shown in Fig. 2, while Fig. 3 shows the average spectra from a region of the stroma under normal epithelium and from the stroma from under diseased epithelium. The spectral differences between normal cervical epithelium and HPV changes within the same sample are fairly subtle. From Fig. 2, slight increases in intensity can be seen at $1334 \mathrm{~cm}^{-1}$ and $1082 \mathrm{~cm}^{-1}$, both of which are usually associated with DNA content of the cell. There are larger spectral differences between the stroma under HPV infected tissue and the stroma under normal tissue, as shown in Fig. 3. Peak intensities are higher under the normal tissue in regions from $1000 \mathrm{~cm}^{-1}$ to $1100 \mathrm{~cm}^{-1}$ and from $1250 \mathrm{~cm}^{-1}$ to $1350 \mathrm{~cm}^{-1}$.

\subsection{Clinical skin study}

The Raman spectra gathered from skin (not shown) were correctly classified by probabilistic statistical methods for all 21 lesion spectra, and for 19 out of the 21 perilesional normals. However, morphometric measurements of the H\&E stained lesion cross sections revealed that nearly all of the lesions manifested at depths greater than the Raman measurement depth. Table 2 shows the measured distances from the skin surface to the proximal margin of the lesion, as well as the axial thickness of each lesion for all of the pathologic lesions studied ( 8 of the 21 suspected nonmelanomas were histopathologically classified as scar tissue). In 


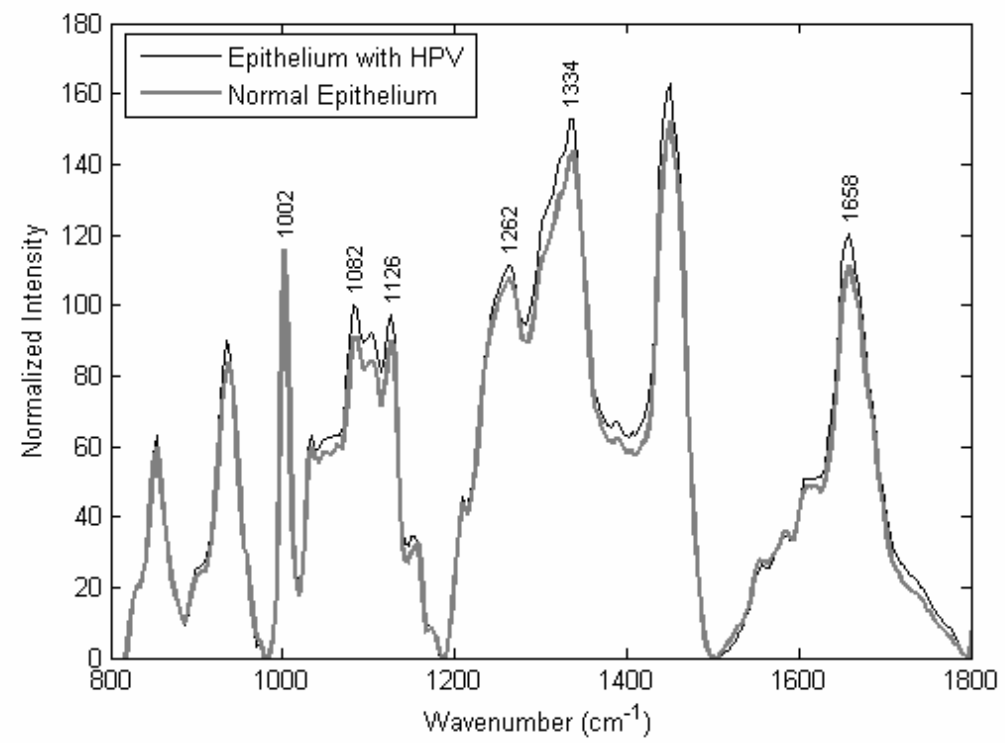

Fig. 2. Average Raman spectra from the epithelium of HPV-infected cervical tissue and from normal epithelial cervical tissue.

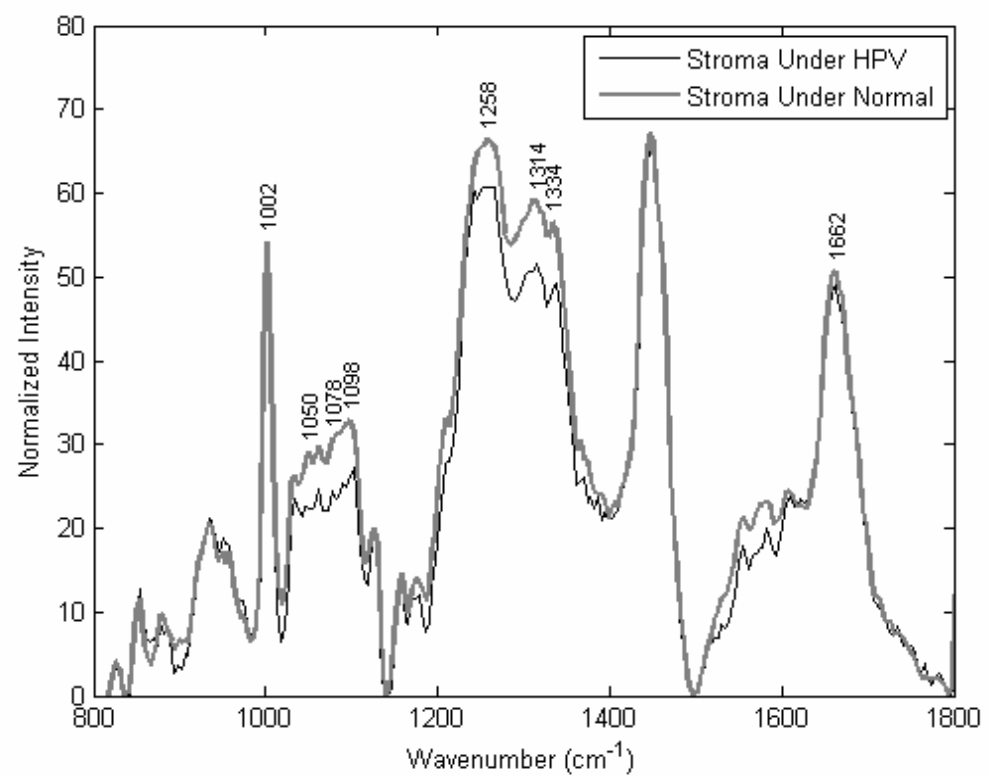

Fig. 3. Average Raman spectra from the stroma under HPV-infected cervical tissue and from the stroma under normal cervical tissue.

some cases, erosion of the skin's uppermost stratum corneum layer during histological preparation prevented absolute quantification. Yet, from this table, it is clearly observed that nearly all of the morphometrically measurable skin lesions presented at depths greater than the $\sim 47 \mu \mathrm{m}$ measurement depth (40 $\mu$ m depth of focus $+1 / 2$ the $14 \mu \mathrm{m}$ axial resolution).

\subsection{Raft culture results}

Representative histology images of each type of raft culture (normal, SCC in epidermis only, and SCC in dermis only) are shown in Fig. 4. Unfortunately, raft cultures are very prone to histology artifacts, as seen especially in Fig. 4B, but useful information can still 
Table 2

Morphometric measurements of nonmelanoma skin cancers showing the distance from the skin surface to the proximal tumor margin and the measured axial thickness of the tumor. Erosion of the stratum corneum during histoprep prevented such measurements in some cases, as noted

\begin{tabular}{cccc}
\hline Sample & Pathology & Proximal margin depth $(\mu \mathrm{m})$ & Tumor thickness $(\mu \mathrm{m})$ \\
\hline 1 & BCC & 89 & 839 \\
2 & BCC & 0 & 554 \\
3 & BCC & erosion & - \\
4 & BCC & erosion & - \\
5 & BCC & 234 & 628 \\
6 & BCC & 593 & 394 \\
7 & BCC & 49 & 697 \\
8 & BCC & 169 & 359 \\
9 & BCC & 888 & 707 \\
10 & SCC & erosion & - \\
11 & SCC & erosion & - \\
12 & SCC & erosion & - \\
13 & SCC & 223 & 110 \\
\hline
\end{tabular}

be extracted. It is clear from these images that epidermal or dermal (stroma) layers that began as normal or cancerous still appeared that way in these histology images, regardless of the spectroscopic findings discussed below. That is, the epidermal layer of the stromal disease raft in Fig. 4B looks much more like the true normal epidermis from Fig. 4A than the cancerous epidermis from Fig. 4C. Similarly, the dermal layer under the cancerous epidermis from Fig. 4C looks normal, like the dermis from Fig. 4A, rather than like the cancerous dermis seen in Fig. 4B, which contains several clusters of SCC cells.

Since Raman spectra obtained at day 20 after raft formation tended to show the most distinction among the three types of rafts, and histology showed the most "complete" models at this time point, measurements from only day 20 of three different sets of experiments were considered for further analysis. Figs 5 and 6 show the mean Raman spectra obtained from separated epidermis and dermis layers, respectively, from a total of six samples each of the three types of rafts. Using ANOVA and t-tests at the .01 significance level, a number of the observed spectral differences in the epidermal only measurements in Fig. 5 are statistically significant. Some of the most prominent and informative results are found around the $1085 \mathrm{~cm}^{-1}$ and $1650 \mathrm{~cm}^{-1}$ peaks and in the 1300 to $1330 \mathrm{~cm}^{-1}$ region, where spectra from both raft types containing SCC cells are identical, but different from the normal rafts. These spectral regions are generally associated with DNA and protein content of cells. Regions where all three spectra statistically differ from one another include the $1450 \mathrm{~cm}^{-1}$ peak and the $1350 \mathrm{~cm}^{-1}$ shoulder, although these differences are not as dramatic. From Fig. 6, the spectral differences for stromal layer measurements from the three kinds of rafts were more substantial on the whole compared with the epidermal results. At essentially all major peaks and shoulder regions, statistically significant differences could be found among all three classes of rafts.

\section{Discussion}

Raman spectroscopy is a highly sensitive and specific technique used by many researchers to discriminate cancerous tissue from normal epithelial tissue [14-24]. At times, using Raman spectroscopy to discriminate cancerous from other types of tissues does not yield the level of sensitivities and specificities expected based on the apparent ability of Raman spectroscopy to detect subtle biochemical changes. These occasional shortcomings of Raman could actually be explained in terms of its strength, in that it is also very sensitive to temporal and spatial effects exerted on surrounding tissues by cancerous areas, confounding efforts to rigidly classify spectral measurements as having come from a small number of histological based categories. Results from the cervical and skin studies support this idea, and raft culture findings tie these studies together.

The results from the clinical cervix study show that previous disease has a significant effect on the Raman signatures of the cervix. These spectra allowed for near $100 \%$ classification by probabilistic statistical methods for discriminating previous disease versus a true normal. Many small differences can be seen in the spectra in Fig. 1, but the largest difference occurs at $1250 \mathrm{~cm}^{-1}$, where the spectra from the previous abnormal are less intense than the true normal peak. This difference could be due to a small amount of collage- 
A

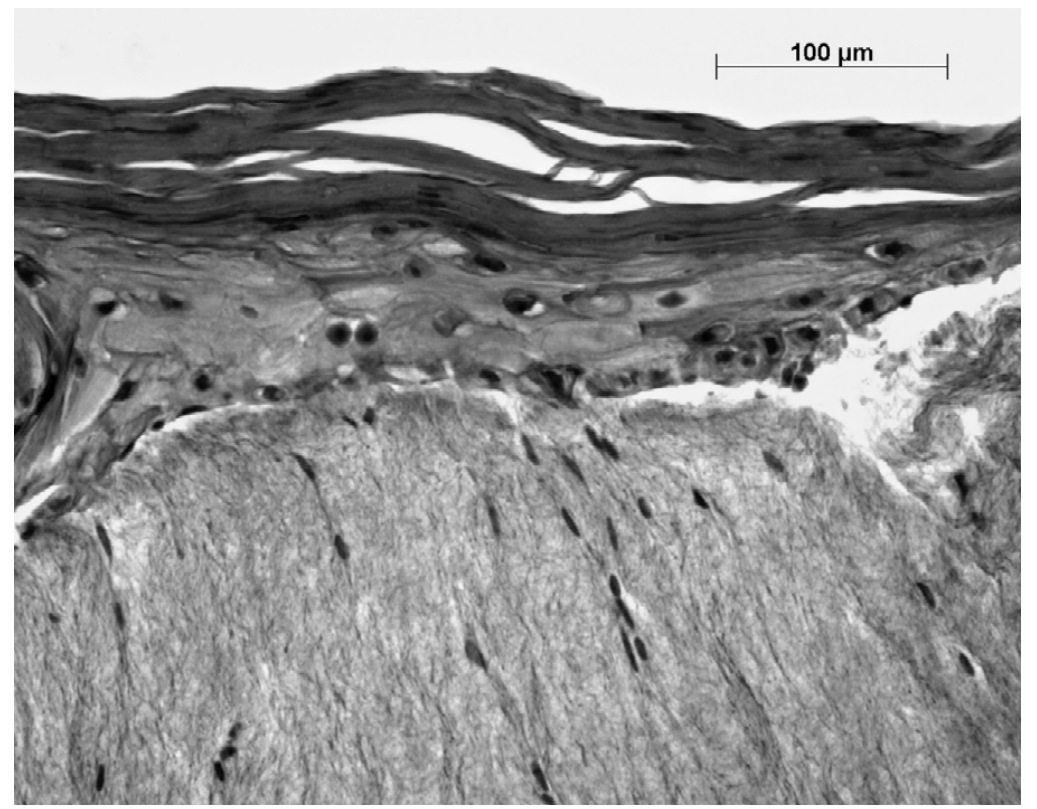

B

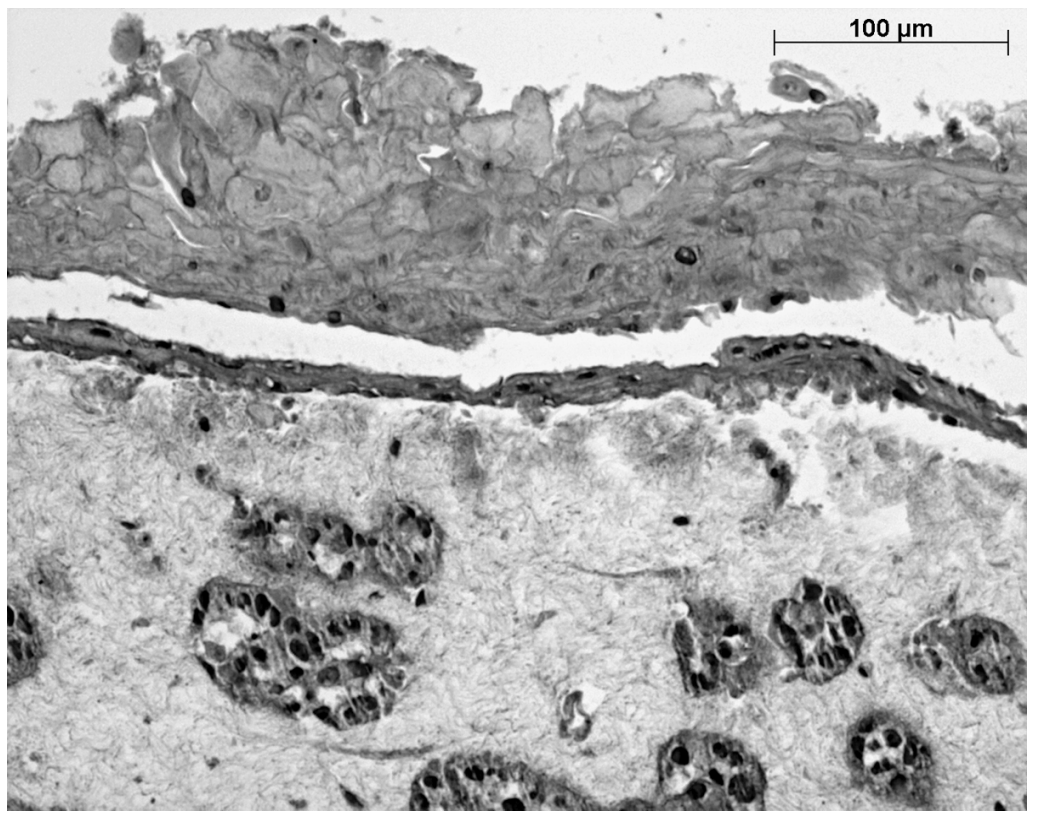

Fig. 4. Representative histological images of (A) normal raft culture; (B) raft culture with normal epidermis and SCC cells in dermis; and (C) raft culture with normal dermis and SCC cells in epidermis.

nous tissue left around the area where the disease had been, since the $1250 \mathrm{~cm}^{-1}$ peak is typically associated with collagen, or due to a number of other malignancy associated changes that never went away but remained undetected by standard means. In a similar manner, previous studies have shown that it is possible to detect new disease once it has started to develop, even if disease has already occurred and then regressed or has been treated [58]. Since Raman spectroscopy has strong prospects for use as a screening method for cervical disease, these findings need to be considered to properly account for all sources of variation in spectra and achieve the best diagnostic performance. However, if Raman is used to guide biopsies, as during col- 
C

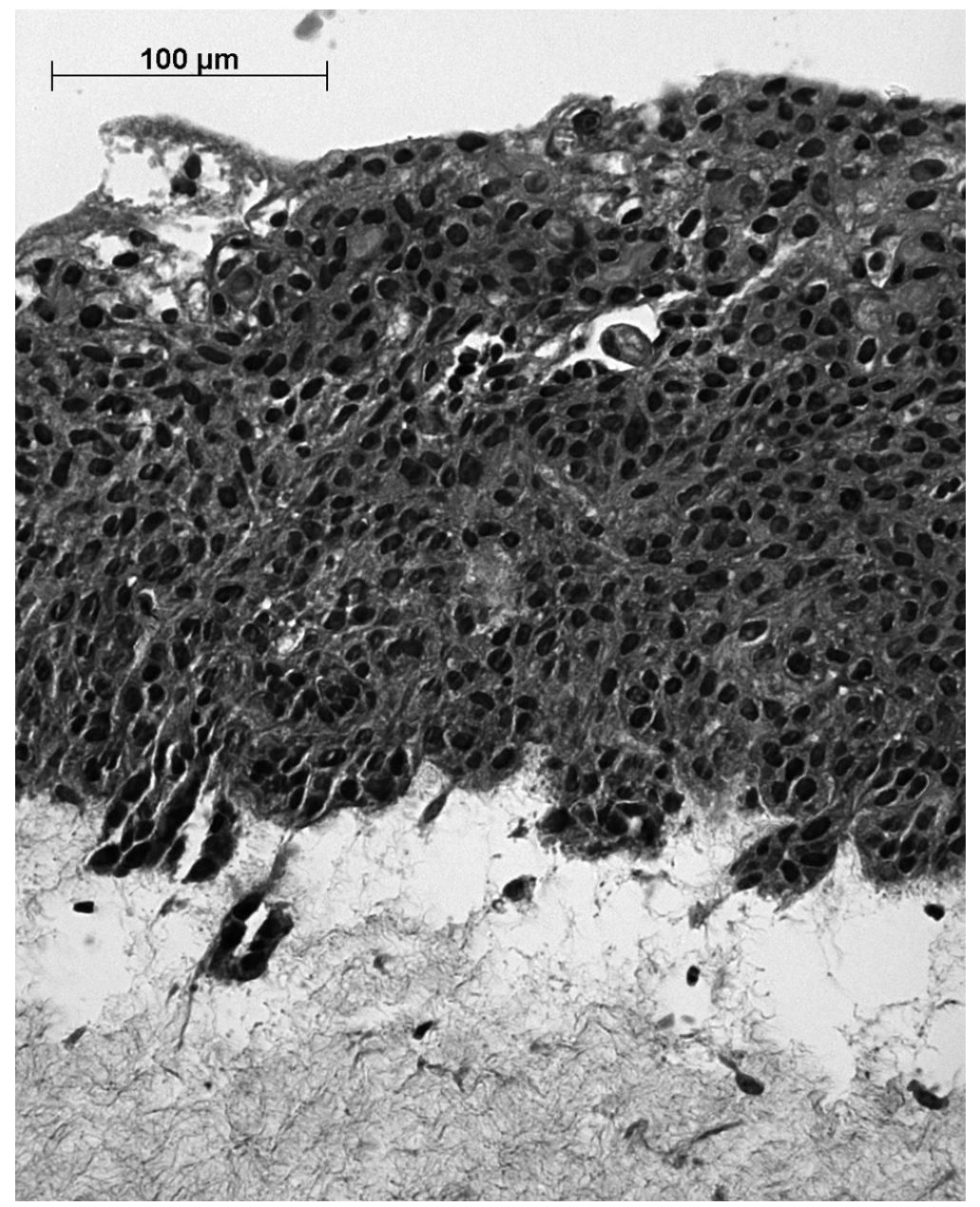

Fig. 4, continued.

poscopy, these findings do not need to be considered because these cervices all have current evidence of disease.

The time point at which one can detect the formation or spread of disease is an important ongoing research topic. From Figs 2 and 3, it appears possible that Raman spectroscopy can detect changes due to adjacent regions of dysplasia or HPV that cannot be detected histologically. In the diseased cervix sample studied, dysplasia only directly affects a portion of the surface epithelium, and no evidence of disease was found in the stroma by a trained pathologist. In Fig. 2, spectral differences are seen between the epithelium of a normal versus a diseased cervix. This cervix had very mild disease (HPV changes), so Raman spectral differences originating from the epithelium were expected. Some of the most prominent changes can be associated with DNA, particularly the region around $1334 \mathrm{~cm}^{-1}$ [59]. It is expected that as a tissue starts to become more active, and in this case more dysplastic, the amount of cellular proliferation and therefore the amount of DNA should increase. This change is fairly subtle in Fig. 2 since there is a minimal amount of disease present; in fact, this type of disease may regress back to histologically normal if left untreated.

The changes that are seen in the average Raman spectra from the stroma below HPV infected tissue and from the stroma below normal tissue, shown in Fig. 3, are more unexpected than what is seen in Fig. 2. In Fig. 3, two spectral regions of stroma below a normal are more intense compared to those from stroma below the diseased area, suggesting that disease in the epithelium can indirectly affect the underlying cervix. Some of the peak differences include those at $1316 \mathrm{~cm}^{-1}$ and $1334 \mathrm{~cm}^{-1}$, which are associated with DNA [60], and at those associated with glycogen $-1048 \mathrm{~cm}^{-1}$, 


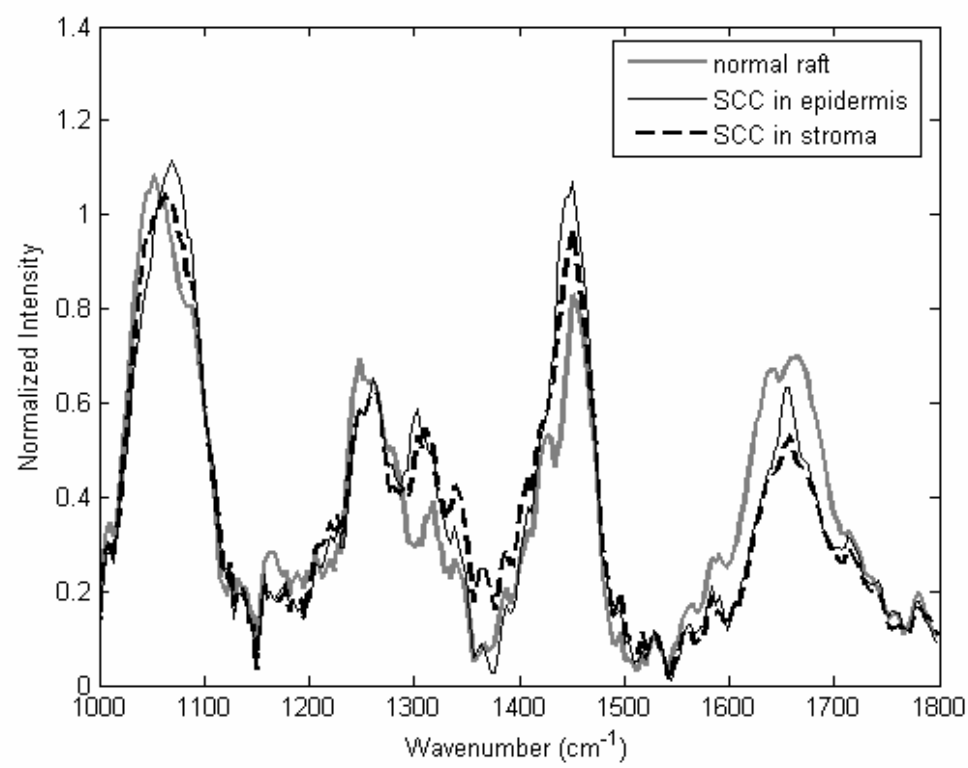

Fig. 5. Mean Raman spectra from the separated epidermis layers only of normal rafts, of rafts with SCC cells in the epidermis only, and of rafts with SCC cells in the stroma only. Each spectrum is an average of three measurements taken from two different rafts over three sets of experiments.

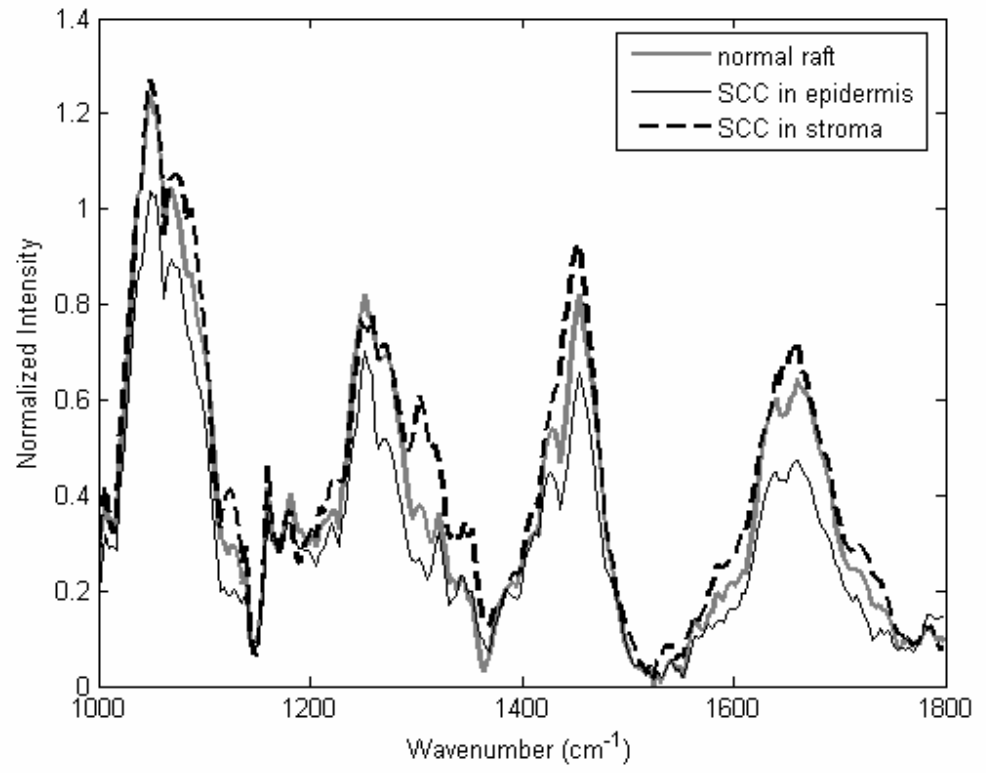

Fig. 6. Mean Raman spectra from the separated stroma (dermis) layers only of normal rafts, of rafts with SCC cells in the epidermis only, and of rafts with SCC cells in the stroma only. Each spectrum is an average of three measurements taken from two different rafts over three sets of experiments.

$1083 \mathrm{~cm}^{-1}, 1256 \mathrm{~cm}^{-1}$, and $1333 \mathrm{~cm}^{-1}$ [61]. It is known that the glycogen in the epithelium decreases with disease [62], but there is no mention of what hap- pens in the stroma as a result of disease in the epithelium. Other spectral differences in Fig. 3 reflect differences in the lipid and protein content of the cervix, the 
latter seen from the peaks at $1260 \mathrm{~cm}^{-1}$ to $1304 \mathrm{~cm}^{-1}$, associated with the Amide III band [60]. Some of these differences used as spectral markers could be due to the nutrients in the blood being used to produce new dysplastic cells, thereby affecting spectra from nearby regions, or it could be that the disease has exerted other effects like MACs on the surrounding tissue without evidencing itself via standard histology. This phenomenon needs to be studied in more detail, as the grading of cervical dysplasia is dependant on the degree of epithelium involvement. As soon as disease invades into the stroma, it is considered cervical cancer, so there could be great interest in detecting early disease markers in the stroma.

More empirical evidence for MACs being detectable by Raman spectroscopy is provided by the clinical skin study. With the Raman microspectrometer focused at a depth $40 \mu \mathrm{m}$ below the surface, the diagnostic algorithm was able to discriminate between normal tissue and lesions with a high rate of success. As shown in Table 2, however, nearly all of the lesions studied were actually situated several hundred microns below the surface, with histologically normal tissue overlying them. Although scattering and refractive index changes may account for some broadening of the measurement depth, such explanations would not account for the diagnostic success of the Raman technique in the majority of the lesions where the proximal margin was from around four to greater than 20 times deeper than the depth of focus. For this reason, it is postulated that the Raman spectra may be detecting MACs in the tissues surrounding the tumors, and experiments are currently underway to test this hypothesis.

The results of the raft cultures studies provide support for both the skin and the in vitro cervix results. The relationships among the mean Raman signatures of the separated epidermal and stromal layers, respectively, of the rafts are shown in Figs 5 and 6, while representative histological images of the different kinds of rafts are shown in Fig. 4. From Fig. 6, the dermal spectral signatures of rafts with normal dermis layers were significantly different compared with the stromal signatures of the rafts with cancerous dermis layers, especially in the region of 1300 to $1320 \mathrm{~cm}^{-1}$, which is often increased in cancerous tissues. Comparing the dermal layers in Fig. 4A and 4B, this result is unsurprising, as the pockets of SCC cells in the dermis of Fig. 4B are quite visible as clusters of dense, nucleated, dysplastic cells. A more interesting comparison is between the dermal layers from the normal rafts and from the rafts with only epidermal disease. In Fig. 4 (A and C), these dermal layers both appear normal, but as Fig. 6 shows, the Raman spectra from the stroma under the diseased epidermis are different from the "true normal" stroma in much the same way as for the cervical measurements in Fig. 3. Although instrumentation and tissue differences lead to fairly different spectra between the two figures, in each, the most prominent difference is a lower intensity from about 1200 to $1350 \mathrm{~cm}^{-1}$ for the spectra obtained from underneath disease rather than under normal surface epithelia. A likely explanation again is that the diseased epidermis is exerting some effect on the histologically normal stroma.

The results of the skin study are supported by the finding that Raman spectra from the epidermal layer of rafts with SCC cells in either their epidermis or dermis layer are nearly equivalent, as seen in Fig. 5, and that both are distinct from the epidermal Raman signature of normal rafts. As discussed above, the skin study was able to discriminate lesions from healthy tissues even when the lesions were deep in the tissue below a sizeable layer of epidermis. As shown in Fig. 4B, placing SCC cells in the dermis of raft cultures mimicked this situation by forming characteristic clusters like they would in a tumor. This figure also shows that the epidermis of these rafts does not visually resemble the epidermis of the epidermal disease rafts in Fig. 4C, even though they possess similar Raman signatures, but it does more closely resemble the epidermis of the normal raft in Fig. 4A, which has a notably different Raman signature. It appears that when the SCC cells are seeded in the stroma, they produce some sort of biochemical signal that both draws the cells together in clusters (this behavior is not evidenced until day 15 after formation) and influences the epidermal cells above them to undergo malignancy associated changes or produce other disease markers that are detectable with Raman spectroscopy, but not with a conventional histology preparation.

Several points still need to be addressed with regard to raft cultures to make them even more useful for future use in elucidating MAC-related mechanisms. Raft cultures are good models of skin (or cervix), both structurally and spectroscopically, but they are not perfect. There are no blood vessels or inflammatory cells in the dermis, and there is no basement membrane between the epidermis and dermis. The latter fact may be relevant in this case not only because of a missing component that may contribute to in vivo Raman signals, but also because its presence may affect the transmission of any biochemical signals between the dermis and epidermis. On the other hand, this lack of a barrier 
may speed up the process to be more viable for study in a lab setting. Instrumentation limitations at the time of this study prevented the gathering of depth-resolved data on intact rafts, which would be another solid piece of supporting evidence for these findings and for the in vivo skin findings.

The four studies presented in this paper add to the growing body of evidence that optical spectroscopy, in this case Raman, can detect subtle temporal and spatial effects in tissue near cancerous sites that go otherwise undetected by conventional histology. The primary temporal effect explored in this paper is the finding that for a patient with a history of disease who is currently healthy, her Raman spectra still show significant differences compared with someone who has never had disease, and that these effects extend over many years. Thus, it is very important to study this effect in other organs or tissue systems, especially those that are prone to multiple instances of disease progression and regression during a lifetime, so that proper "normal" baselines can be set when making any attempt at tissue discrimination.

It would also be interesting to examine the temporal aspects of the various spatial effects discussed in this paper. As shown for cervix, skin, and an epithelial tissue model, histologically normal tissues located near tumors show distinct Raman spectral differences from normal tissues located further away or in completely healthy systems. What remains to be seen is at what time point these spatial effects are first detectable, and whether areas showing these effects will eventually become cancerous as well, or simply continue functioning in a quasi-normal but altered state. Raft cultures would be an ideal starting point for this kind of study because they can be plentifully made, are easy to interrogate optically, and can be made in several different configurations of normal versus various types of diseased cells. These findings would have a significant impact on the development of early screening techniques, which could provide great benefit to patients down the line. These spatial effects also have an impact on choosing what kind of tissue to use as a normal reference in discrimination studies, as it must be determined whether a "true normal" measurement is even possible from a patient with disease, and if so, how much distance from the diseased site is required to ensure accurate results.

Although the results presented in this paper are hypothesized to be due to malignancy associated changes or a cancer field effect, optical spectroscopy is not necessarily the answer for elucidating such mechanisms.
Rather, it excels as a tool to detect such subtle tissue changes and disease markers, and it is important to work with those in more purely biological fields in determining what cellular and stromal changes are actually occurring, which could then lead to more focused detection techniques and the improved ability to detect early tissue changes related to the development of cancer.

\section{Acknowledgments}

The authors acknowledge the financial support of the NCI/NIH (R01-CA95405 and R21-CA95995), as well as the Howard Hughes Medical Institute (pre-doctoral fellowship for MK). We would also like to thank the doctors and staff at Vanderbilt University Medical Center and Tri-state Women's Health for all their assistance.

\section{References}

[1] S.J. Miller, R.M. Lavker and T.-T. Sun, Interpreting epithelial cancer biology in the context of stem cells: Tumor properties and therapeutic implications, Biochimica et Biophysica Acta (BBA) - Reviews on Cancer 1756 (2005), 25-52.

[2] A.C.S, Cervical Cancer Resource Center, American Cancer Society, 2007.

[3] T. Wright, R.J. Kurman and A. Ferenczy, Cervical Intraepithelial Neoplasia, in: Blaustien's Pathology of the Female Genital Tract, Springer-Verlag, ed., New York, 1994.

[4] I. Ramzy, Essentials of Gynecologic and Obstetric Pathology, Appleton - Century - Crofts, Norwalk, 1983.

[5] J.L.H. Evers and M.J. Heineman, Gynecology - A Clinical Atlas, CV Mosby Co, St.Louis, 1990.

[6] J.H. Farley, J.F. Hines, R.R. Taylor, J.W. Carlson, M.F. Parker, E.R. Kost, S.J. Rogers, T.A. Harrison, C.I. Macri and G.P. Parham, Equal care ensures equal survival for AfricanAmerican women with cervical carcinoma, Cancer 91 (2001), 869-873.

[7] G.H. Anderson, D.A. Boyes, J.L. Benedet, J.C. Le Riche, J.P. Matisic, K.C. Suen, A.J. Worth, A. Millner and O.M. Bennett, Organisation and results of the cervical cytology screening programme in British Columbia, 1955-1985, Br Med J (Clin Res Ed) 296 (1988), 975-978.

[8] L. Burke, D.A. Antonioli and B.S. Ducatman, Colposcopy, text and atlas, Appleton and Large, Norwalk, 1991.

[9] K. Nanda, D.C. McCrory, E.R. Myers, L.A. Bastian, V. Hasselblad, J.D. Hickey and D.B. Matchar, Accuracy of the Papanicolaou test in screening for and follow-up of cervical cytologic abnormalities: a systematic review, Ann Intern Med 132 (2000), 810-819.

[10] M.T. Fahey, L. Irwig and P. Macaskill, Meta-analysis of Pap test accuracy, Am J Epidemiol 141 (1995), 680-689.

[11] U. Minoru, Cervical Adenocarcinoma: A Colscopic Atlas, Ishiyaku - EuroAmerica Inc., St. Louis, 1985.

[12] M. Mitchell, Accuracy of Colposcopy, Consultations in Obstetrics and Gynecology 6 (1994). 
[13] I. Freedberg, Ftizpatrick's Dermatology in General Medicine, 6th ed., McGraw Hill, 2003.

[14] A. Mahadevan-Jansen, M.F. Mitchell, N. Ramanujam, A. Malpica, S. Thomsen, U. Utzinger and R. Richards-Kortum, Near-infrared Raman spectroscopy for in vitro detection of cervical precancers, Photochem Photobiol 68 (1998), 123 132.

[15] A. Mahadevan-Jansen, M.F. Mitchell, N. Ramanujam, U. Utzinger and R. Richards-Kortum, Development of a fiber optic probe to measure NIR Raman spectra of cervical tissue in vivo, Photochem Photobiol 68 (1998), 427-431.

[16] P. Crow, A. Molckovsky, N. Stone, J. Uff, B. Wilson and L.M WongKeeSong, Assessment of fiberoptic near-infrared raman spectroscopy for diagnosis of bladder and prostate cancer, Urology 65 (2005), 1126-1130.

[17] Z. Huang, A. McWilliams, H. Lui, D.I. McLean, S. Lam and H. Zeng, Near-infrared Raman spectroscopy for optical diagnosis of lung cancer, Int J Cancer 107 (2003), 1047-1052.

[18] C. Lieber, S. Majumder, D. Ellis, D. Billheimer and A. Mahadevan-Jansen, In vivo nonmelanoma skin cancer diagnosis using Raman microspectroscopy, Lasers Surg Med (2008).

[19] S. Sigurdsson, P.A. Philipsen, L.K. Hansen, J. Larsen, M. Gniadecka and H.C. Wulf, Detection of skin cancer by classification of Raman spectra, IEEE Trans Biomed Eng 51 (2004), 1784-1793.

[20] M.V. Chowdary, K.K. Kumar, J. Kurien, S. Mathew and C.M. Krishna, Discrimination of normal, benign, and malignant breast tissues by Raman spectroscopy, Biopolymers 83 (2006), 556-569.

[21] A.S. Haka, K.E. Shafer-Peltier, M. Fitzmaurice, J. Crowe, R.R. Dasari and M.S. Feld, Diagnosing breast cancer by using Raman spectroscopy, Proc Natl Acad Sci USA 102 (2005), 12371-12376.

[22] G. Shetty, C. Kendall, N. Shepherd, N. Stone and H. Barr, Raman spectroscopy: elucidation of biochemical changes in carcinogenesis of oesophagus, Br J Cancer 94 (2006), 14601464.

[23] M.G. Shim, L.M. Song, N.E. Marcon and B.C. Wilson, In vivo near-infrared Raman spectroscopy: demonstration of feasibility during clinical gastrointestinal endoscopy, Photochem Photobiol 72 (2000), 146-150.

[24] A. Molckovsky, L.M. Song, M.G. Shim, N.E. Marcon and B.C. Wilson, Diagnostic potential of near-infrared Raman spectroscopy in the colon: differentiating adenomatous from hyperplastic polyps, Gastrointest Endosc 57 (2003), 396-402.

[25] A. Robichaux-Viehoever, E. Kanter, H. Shappell, D. Billheimer, H. Jones and A. Mahadevan-Jansen, Characterization of Raman spectra measured in vivo for the detection of cervical dysplasia, Applied Spectroscopy 61 (2007), 986-993.

[26] C.M. Krishna, N.B. Prathima, R. Malini, B.M. Vadhiraja, R.A. Bhatt, D.J. Fernandes, P. Kushtagi, M.S. Vidyasagar and V.B. Kartha, Raman spectroscopy studies for diagnosis of cancers in human uterine cervix, Vibrational Spectroscopy 41 (2006), 136-141.

[27] E.M. Kanter, S.K. Majumder, G.J. Kanter, E.M. Woeste and A. Mahadevan-Jansen, Effect of hormonal variation on Raman spectra for cervical disease detection, American Journal of Obstetrics and Gynecology (in press).

[28] E.M. Kanter, E. Vargis, S.K. Majumder, M.D. Keller, G.J. Kanter, G.G. Rao and A. Mahadevan-Jansen, Application of Raman Spectroscopy for Cervical Dysplasia Diagnosis, Journal of Biophotonics (in review).

[29] H.C.W.M. Gniadecka, N. Nymark Mortensen, O. Faurskov Nielsen and D.H. Christensen, Diagnosis of Basal Cell Car- cinoma by Raman Spectroscopy, Journal of Raman Spectroscopy 28 (1997), 125-129.

[30] A. Nijssen, T.C. Bakker Schut, F. Heule, P.J. Caspers, D.P. Hayes, M.H. Neumann and G.J. Puppels, Discriminating basal cell carcinoma from its surrounding tissue by Raman spectroscopy, J Invest Dermatol 119 (2002), 64-69.

[31] J. Choi, J. Choo, H. Chung, D.G. Gweon, J. Park, H.J. Kim, S. Park and C.H. Oh, Direct observation of spectral differences between normal and basal cell carcinoma (BCC) tissues using confocal Raman microscopy, Biopolymers 77 (2005), 264 272.

[32] M. Gniadecka, P.A. Philipsen, S. Sigurdsson, S. Wessel, O.F. Nielsen, D.H. Christensen, J. Hercogova, K. Rossen, H.K. Thomsen, R. Gniadecki, L.K. Hansen and H.C. Wulf, Melanoma diagnosis by Raman spectroscopy and neural networks: structure alterations in proteins and lipids in intact cancer tissue, J Invest Dermatol 122 (2004), 443-449.

[33] C. Lieber and A. Mahadevan-Jansen, Development of a handheld Raman microspectrometer for clinical dermatologic applications, Opt Express 15 (2007), 11874-11882.

[34] C.A. Lieber, S.K. Majumder, D. Billheimer, D.L. Ellis and A. Mahadevan-Jansen, Raman microspectroscopy for skin cancer detection in vitro, Journal of Biomedical Optics 13 (2008).

[35] E. Giovannucci and S. Ogino, DNA methylation, field effects, and colorectal cancer, J Natl Cancer Inst 97 (2005), 13171319.

[36] D. Slaughter, H. Soutwhick and W. Smejkal, Field Cancerization in Oral Stratified Squamous Epithelium - Clinical Implications of Multicentric Origin, Cancer 6 (1953), 963-968.

[37] H.E. Nieburgs, Recent progress in the interpretation of malignancy associated changes (MAC), Acta Cytol 12 (1968), 445-453.

[38] H.E. Nieburgs, B.E. Herman and H. Reisman, Buccal cell changes in patients with malignant tumors, Lab Invest $\mathbf{2}$ (1962), 80-88.

[39] H.E. Nieburgs, A.F. Goldberg, B. Bertini, J. Silagi, B. Pacheco and H. Reisman, Malignancy associated changes (MAC) in blood and bone marrow cells of patients with malignant tumors, Acta Cytol 11 (1967), 415-423.

[40] M. Us-Krasovec, J. Erzen, M. Zganec, M. Strojan-Flezar, J. Lavrencak, D. Garner, A. Doudkine and B. Palcic, Malignancy associated changes in epithelial cells of buccal mucosa: a potential cancer detection test, Anal Quant Cytol Histol 27 (2005), 254-262.

[41] R.M. Sacile, E. Ruggiero, C. Nieburgs, H.E. Nicolo, G., A decision support system to detect morphologic changes of chromatin arrangement in normal-appearing cells, IEEE Trans Nano Bioscience 2 (2003), 118-123.

[42] N. Ikeda, C. MacAulay, S. Lam, J. LeRiche, P. Payne, D. Garner, C. Konaka, H. Kato and B. Palcic, Malignancy associated changes in bronchial epithelial cells and clinical application as a biomarker, Lung Cancer 19 (1998), 161-166.

[43] M. Guillaud, D. Cox, K. Adler-Storthz, A. Malpica, G. Staerkel, J. Matisic, D. Van Niekerk, N. Poulin, M. Follen and C. MacAulay, Exploratory analysis of quantitative histopathology of cervical intraepithelial neoplasia: objectivity, reproducibility, malignancy-associated changes, and human papillomavirus, Cytometry A 60 (2004), 81-89.

[44] R.A. Kemp, C. MacAulay, D. Garner and B. Palcic, Detection of malignancy associated changes in cervical cell nuclei using feed-forward neural networks, Anal Cell Pathol 14 (1997), $31-40$.

[45] H.U. Kasper, G. Haroske, U. Geissler, W. Meyer and K.D. Kunze, Diagnostic and prognostic relevance of malignancy- 
associated changes in cervical smears, Anal Quant Cytol Histol 19 (1997), 482-488.

[46] C. Mujat, C. Greiner, A. Baldwin, J.M. Levitt, F. Tian, L.A Stucenski, M. Hunter, Y.L. Kim, V. Backman, M. Feld, K. Muenger and I. Georgakoudi, Endogenous optical biomarkers of normal and human papillomavirus immortalized epithelial cells, International Journal of Cancer 122 (2008), 363-371.

[47] N. Anderson, J. Houghton, S.J. Kirk, D. Frank, J. RangerMoore, D.S. Alberts, D. Thompson and P.H. Bartels, Malignancy-associated changes in lactiferous duct epithelium, Anal Quant Cytol Histol 25 (2003), 63-72.

[48] N. Boroday, D. Klyushin, Y. Petunin and R. Andrushkiw, Analysis of malignancy-associated DNA changes in interphase nuclei of buccal epithelium in persons with breast diseases, Exp Oncol 26 (2004), 158-160.

[49] E.C. Mommers, N. Poulin, C.J. Meijer, J.P. Baak and P.J. van Diest, Malignancy-associated changes in breast tissue detected by image cytometry, Anal Cell Pathol 20 (2000), 187-195.

[50] H.K. Roy, Y. Liu, R.K. Wali, Y.L. Kim, A.K. Kromine, M.J. Goldberg and V. Backman, Four-dimensional elastic lightscattering fingerprints as preneoplastic markers in the rat model of colon carcinogenesis, Gastroenterology 126 (2004), 1071-1081; discussion 948.

[51] H.K. Roy, Y.L. Kim, Y. Liu, R.K. Wali, M.J. Goldberg, V. Turzhitsky, J. Horwitz and V. Backman, Risk stratification of colon carcinogenesis through enhanced backscattering spectroscopy analysis of the uninvolved colonic mucosa, Clin Cancer Res 12 (2006), 961-968.

[52] H.K. Roy, V. Turzhitsky, A. Gomes, M.J. Goldberg, J.D. Rogers, Y.L. Kim, T.K. Tsang, D. Shah, M.S. Borkar, M. Jameel, N. Hasabou, R. Brand, Z. Bogojevic and V. Backman, Prediction of colonic neoplasia through spectral marker analysis from the endoscopically normal rectum: An ex vivo and in vivo study, Gastroenterology 134 (2008), A109-A109.

[53] Y. Liu, R.E. Brand, V. Turzhitsky, Y.L. Kim, H.K. Roy, N. Hasabou, C. Sturgis, D. Shah, C. Hall and V. Backman, Optical markers in duodenal mucosa predict the presence of pancreatic cancer, Clinical Cancer Research 13 (2007), 4392-4399.
[54] A.R. Viehoever, D. Anderson, D. Jansen and A. MahadevanJansen, Organotypic raft cultures as an effective in vitro tool for understanding Raman spectral analysis of tissue, Photochem Photobiol 78 (2003), 517-524.

[55] C.A. Lieber and A. Mahadevan-Jansen, Automated method for subtraction of fluorescence from biological Raman spectra, Applied Spectroscopy 57 (2003), 1363-1367.

[56] S.K. Majumder, S. Gebhart, M.D. Johnson, R. Thompson, W.C. Lin and A. Mahadevan-Jansen, A probability-based spectroscopic diagnostic algorithm for simultaneous discrimination of brain tumor and tumor margins from normal brain tissue, Appl Spectrosc 61 (2007), 548-557.

[57] J. Hutchings, C. Kendall, N. Shepherd, H. Barr, B. Smith and N. Stone, Rapid Raman microscopic imaging for potential histological screening, in: Proceedings of SPIE, A. MahadevanJansen, W. Petrich, R.R. Alfano and A. Katz, eds, (6853) 2008, pp. 685305-685309.

[58] E.M. Kanter, S. Majumder, E. Vargis, A. RobichauxViehoever, G.J. Kanter, H. Shappell, H.W.J. III and A. Mahadevan-Jansen, Multi-class discrimination of cervical precancers using Raman spectroscopy, Journal of Raman Spectroscopy, (2008), (In Press).

[59] A. Nijssen, T.C.B. Schut, F. Heule, P.J. Caspers, D.P. Hayes, M.H.A. Neumann and G.J. Puppels, Discriminating basal cell carcinoma from its surrounding tissue by Raman spectroscopy, Journal of Investigative Dermatology 119 (2002), 64-69.

[60] A. Mahadevan-Jansen, W.F. Mitchell, N. Ramanujam, U. Utzinger and R. Richards-Kortum, Development of a fiber optic probe to measure NIR Raman spectra of cervical tissue in vivo, Photochemistry and Photobiology 68 (1998), 427-431.

[61] C. Kendall, A Study of Raman Spectroscopy for the Early Detection and Classification of Malignancy in Oesophageal Tissue, PhD Dissertation, Cranfield University, 2002.

[62] J.W. Sellors and R. Sankaranarayanan, Colpsocopy and Treatment of Cervical Intreaepithelial Neoplasia: A Beginners' Manual, International Agency for Research on Cancer, Lyon, 2003. 


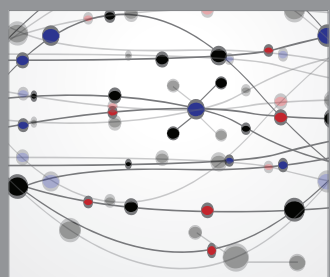

The Scientific World Journal
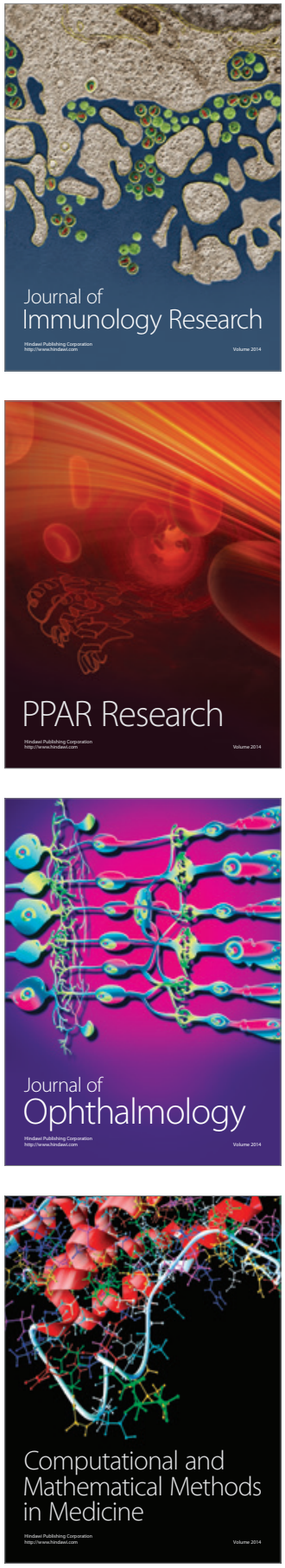

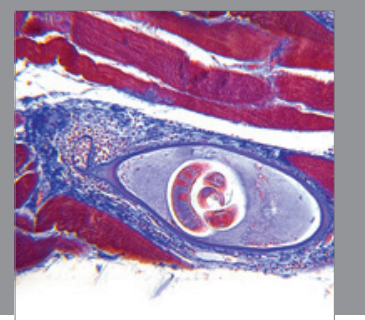

Gastroenterology

Research and Practice
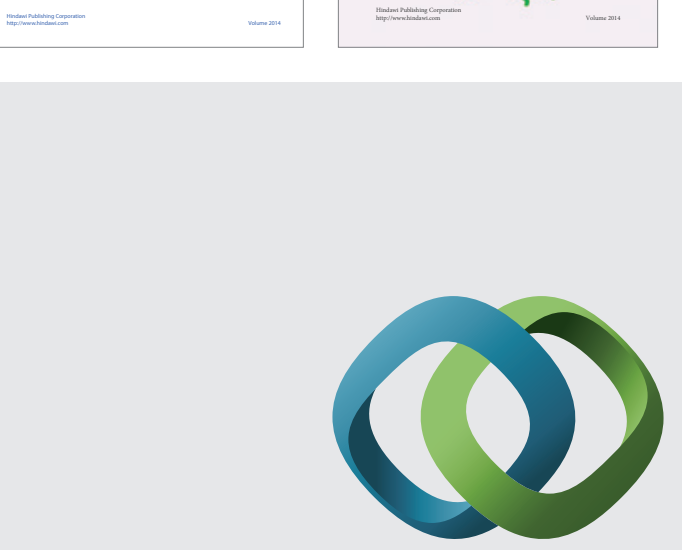

\section{Hindawi}

Submit your manuscripts at

http://www.hindawi.com
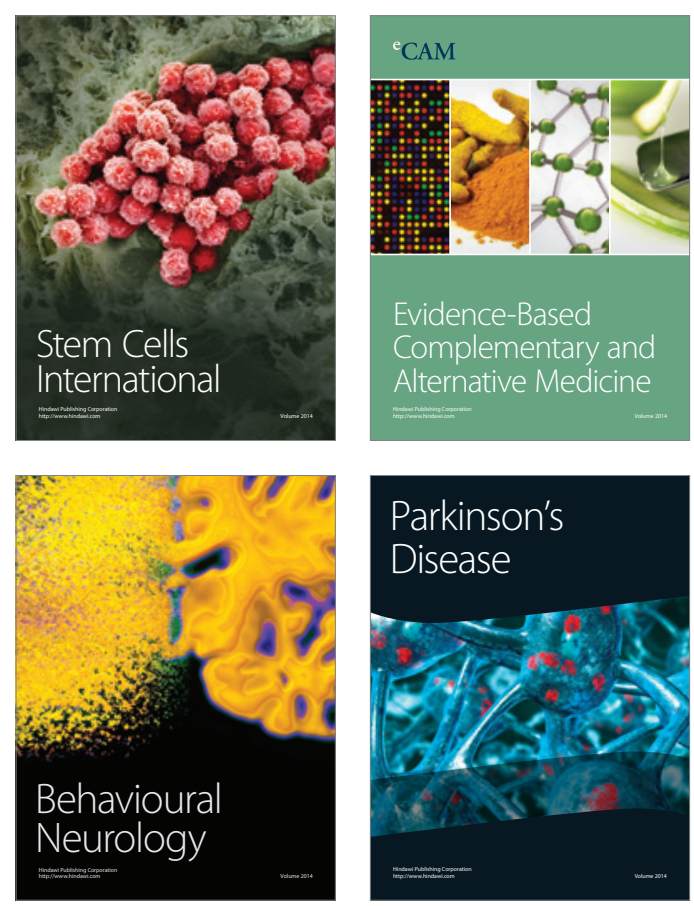

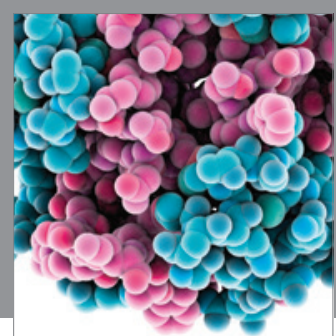

Journal of
Diabetes Research

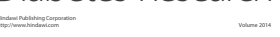

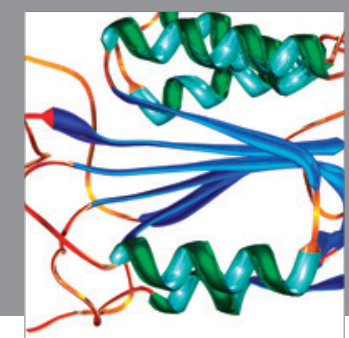

Disease Markers
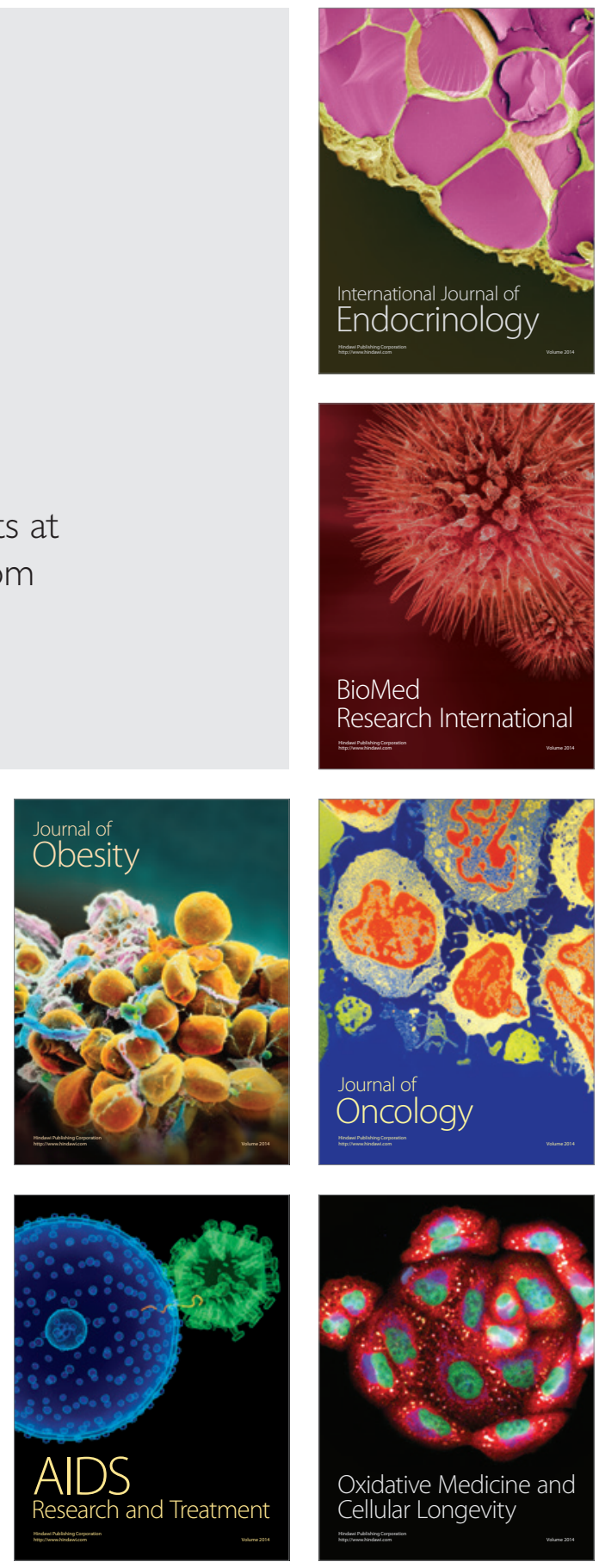